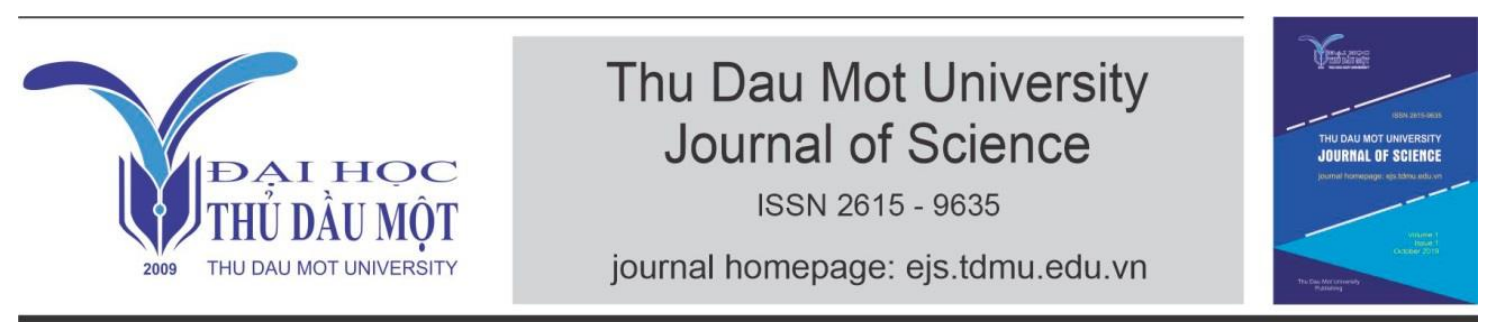

\title{
Research and design a combined model of pile driving and pressing machine
}

by Ngo Bao (Thu Dau Mot University)

Article Info: Received Aug. 20 $0^{\text {th }}$, 2020, Accepted Aug. 27 th 2020 ,Available online Sep. $15^{\text {th }}, 2020$ Corresponding author: ngobaobk@gmail.com (Ngo Bao MA.)

https://doi.org/10.37550/tdmu.EJS/2020.03.068

\begin{abstract}
The paper presents general theory about making small models for studying large machines. Here, the author refers to the design of pile driving and pressing machines. To express ideas, the author presents design drawings presented in three-dimensional perspective. Currently, pile drivers and pile presses are two separate machines, in which their base machine is the same, their working parts are slightly different. The author takes advantage of the slight differences to combine them into one machine, so as to ensure that this machine is able to pile or pile. In addition, the structure of pile making and pressing machines is created by the author, which is somewhat simpler than the current construction and driving machine. This successful study will form the basis for manufacturing a pile driving machine and pile machine into a single machine, greatly reducing the costs of procurement and construction machine use.
\end{abstract}

Keywords: pile driving machine, pile press machine, model, hydraulic cylinder

\section{Introduction}

Before getting to the big, let's start with the small. Before manufacturing a passenger aircraft, the designer must produce a small aircraft model and spend a lot of time learning and testing on that small model. The author of this article, too, plans to build the pile driving machine and the pile press into a single machine. Therefore, the author 
has to build this machine model first. Designing and manufacturing a model that combines the driving machine and the pile press will give us two advantages. Firstly, there is a practical basis for us to research, learn, test, and then have the right direction to build large machines in the future. Second, used as teaching aids for students, because this model is related to the subject "Construction machinery".

During the time studying in the school, students rarely have opportunities to interact with pile driving machines, pile presses. Talking about these machines, the learners only know through the lectures in the lecturers' class, the textbook or the Internet. These machines are high cost, easy to lose safety, unprofessional people, without duties, are not allowed to go near the area where they are working. Therefore, despite the fact that many of these machines have been used, the non-official (especially students) still cannot access to understand them.

Furthermore, the working principle and the internal structure of pile driving machines and pile presses are a curious matter for construction students and all who want to learn. The textbooks have written about them, but only talk about theory, people who do not specialize in machinery (such as students of construction) are difficult to understand if reading. Therefore, it is necessary to have models of these machines for students to study, for teachers and other interested people to have real products to learn and research.

\section{The basis for designing the combined model of pile presses and presses}

Foundations for creation and research: A machine that can do two tasks of driving and pressing piles is unprecedented in the world. Therefore, if the author initially designs and builds a small model of this machine, that small model has never been available. Clearly, this work represents the invention, whose goal is to build a new machine, which is more streamlined and cost-effective than the two machines in use today, the pile driving machine and the press machine pile.

Facilities to make teaching aids: Teaching by real model will be easier for learners to understand than teaching with presentations in class. With a model, students can collide and disassemble their own hands to record knowledge and remember lessons for a long time, even they can remember for a lifetime. But looking at words, drawings in books or looking at documents on the internet is rare for anyone to remember. On the other hand, the teaching model must be safe for learners, not too small or too big. The model as mentioned by the author above is an inexpensive model, not as sophisticated as an electronic computer, not as complicated as an internal combustion engine, an electric motor... Therefore, if we make it small it feels like a children's toy, not suitable for the 
student's age; And when we make it big, it is heavy, easy to lose safety, and the cost is large. So, we choose the model size length $\mathrm{x}$ width $\mathrm{x}$ height about 1 x 1 x 2.5 (meter) is suitable. Said is appropriate because during practice, students do not have to climb high, nor do they have to bend over or squeeze each other to look.

The facility offers the same operating principle as the actual large machines: We cannot have money to buy pile driving machines, pile presses for students to study (because their prices are up to several billion VND), nor is it necessary to buy. We just need to make miniature, analogous models of those machines, and the principle of similar work to those machines is enough for biology. The model we build does not require the required load, productivity or efficiency, but rather about creativity, safety and demonstrating working principles like real machines. Therefore, the calculation for the machine to operate to achieve productivity, speed ... according to requirements, we reduce it, but we increase the aesthetics and selection of standard parts and materials. When a part of a model is damaged, it can be purchased immediately to replace it.

An existing money base: With a budget of not more than 20 million VND (the standard cost for the foundation level topic) for the whole process of designing and manufacturing a satisfactory model of pile driving and pressing machine for students to practice, practice as Working on a large machine is also difficult for the author. All our calculations and designs always think about the cost, how to suit our budget. High expectations, such as: durable, beautiful, performing well, exceeding expectations, we strive to achieve, but being $100 \%$ perfect is difficult. Therefore, the budget greatly affects the design and quality of the products we manufacture.

\section{A brief overview of known pile driving machine and pile press}

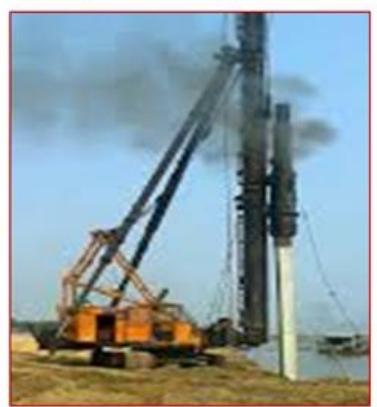

a)

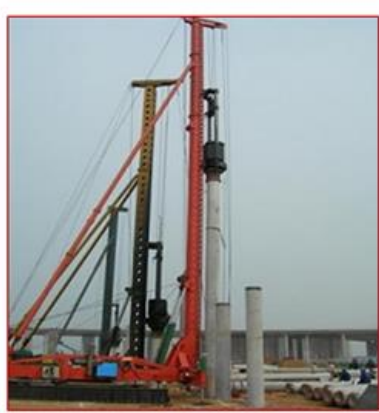

b)

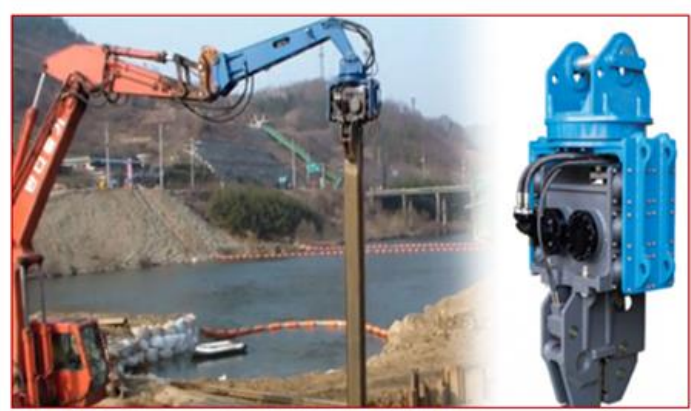

c)

Figure 1. Existing pile driving machines [a) Diesel hammer driving machine; b) Falling hammer type pile driving machine; c) Vibrating hammer driving machine] 
Figures 1 and 2 are pile driving machines, pile presses are used in the construction industry today. Obviously, they are two separate machines, but have a few similar parts that are mutually exclusive. Therefore, the author presents these pictures so that readers can see the previous products and partly understand the author's idea of wanting to combine these two machines into a single machine that can do both tasks is driving and pressing piles in construction.

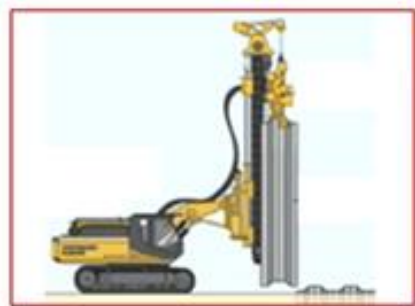

a)

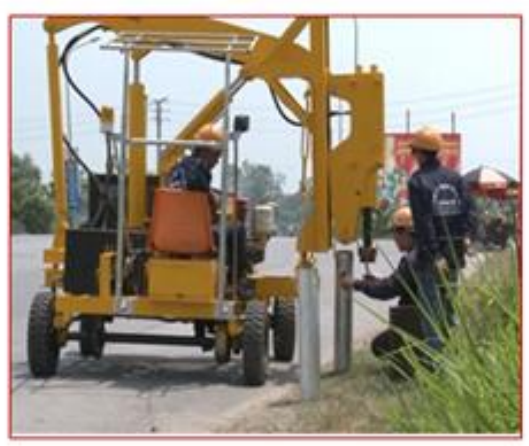

e)

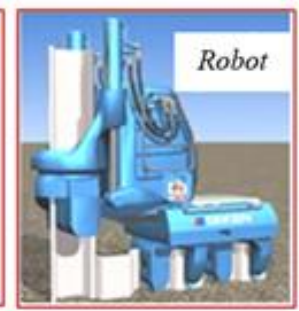

b)

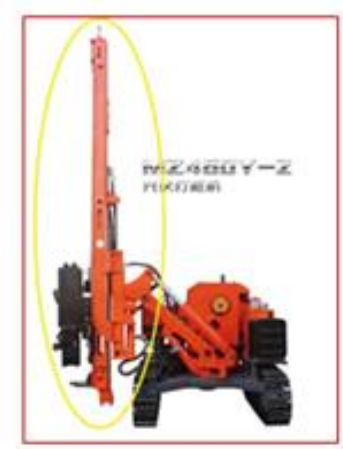

f)

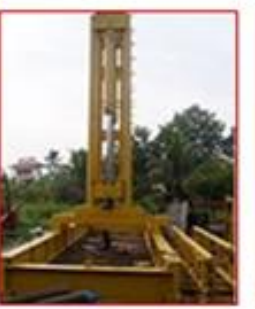

c)
Figure 2. Existing pile presses [a) Metal pile pressing; b) Pile press robot; c) Frame for pressing piles; d) Overview of pile press system; e) Pile driving machine for roads

f) Solar piling machine ; g) Mini piling machine powered by gasoline]

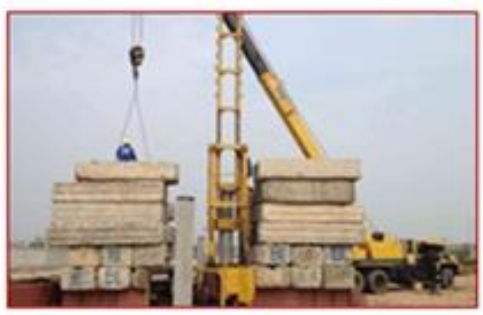

d)

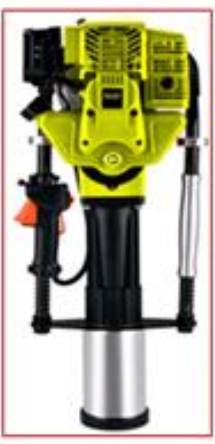

g)

Pile driving machine is a machine using a hammer to apply force to the pile head, causing the pile to sink deeply into the ground; The pile press is a machine that uses force to press on one end of the pile, or clamp the pile body and compress so that the other end of the pile sinks to the ground (Nguyen Van Hung, 2003). Currently, the pile driving machine and the pile press are two separate types of machine. The author has not found a machine that can do two tasks: driving and pressing the pile.

\section{Designing the pile driving machine model}

\section{General description}

The whole machine installation drawing of the driving machine model is as shown in the drawings of Figures 3 and 4 below. It is just a machine, but when using piling, it is 
as shown in figure 3, but when using pile pressing, it is as drawing in figure 4. Descriptions, notes, specifications ... the author performed on the picture, readers easily understand. All results of the author's design focus on these two drawings.

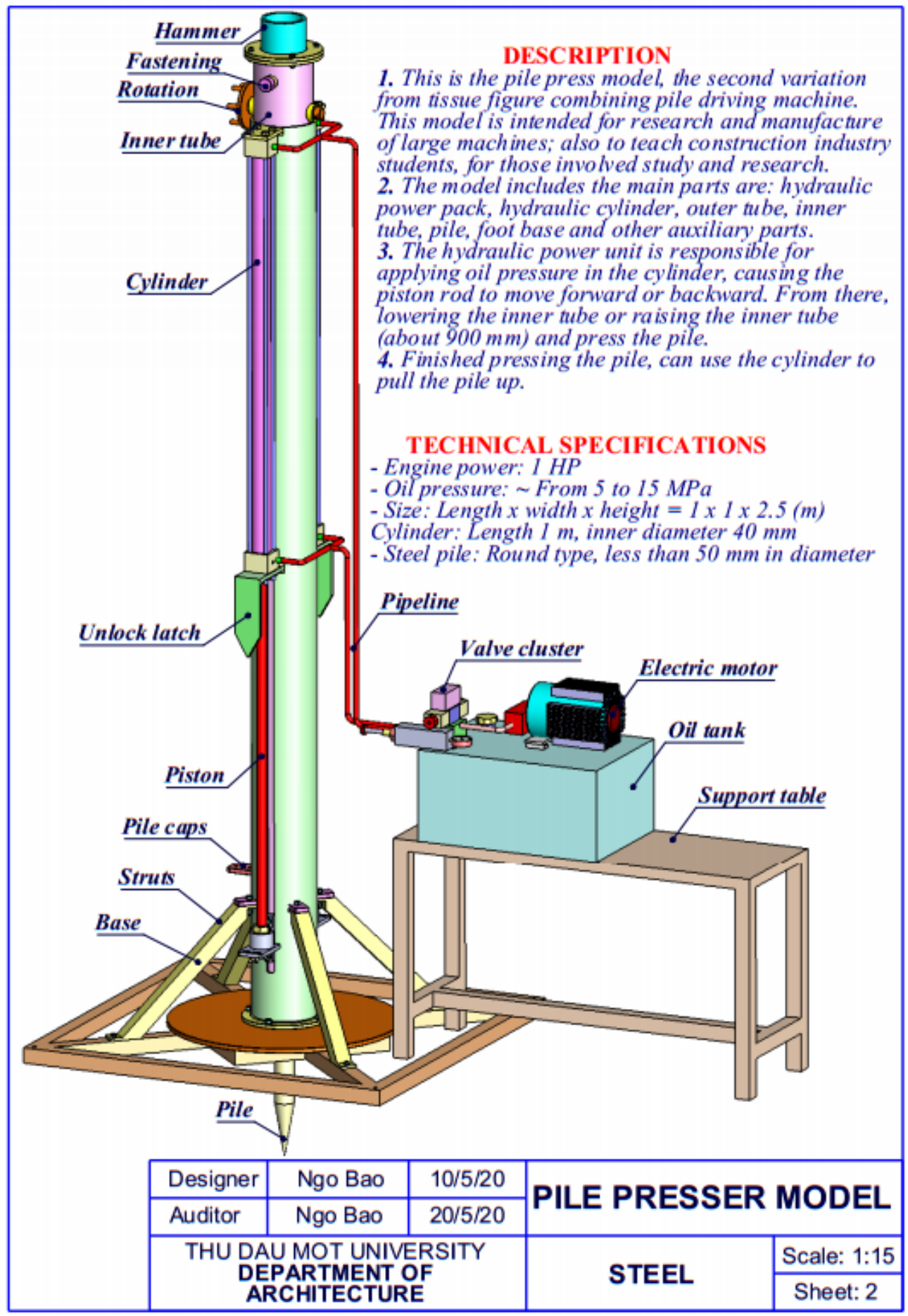

Figure 3. Installation drawing of pile driving machine model 
What's new in this design is to combine two separate machines into a single machine; The working part of this combined model consists of two snug tubes, a fixed tube, a moving pipe up and down to be used for driving and pressing the pile. Both tubes have a groove cut (figure 3) sufficient to insert the stake inside. In this model, the author designed a $60 \mathrm{~mm}$ wide groove, used for driving and pressing round steel piles with a diameter of less than $60 \mathrm{~mm}$.

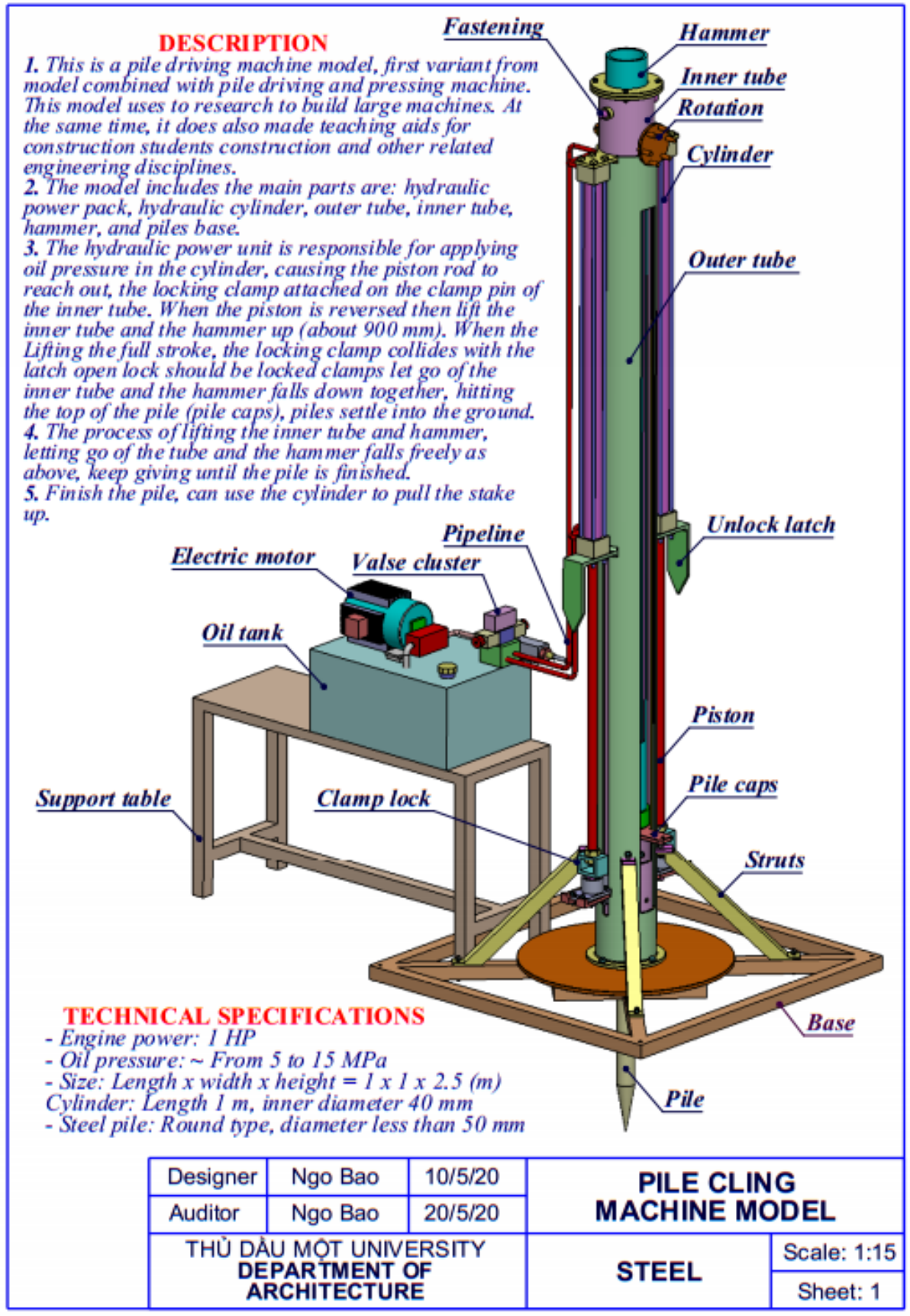

Figure 3. Installation drawing of pile press machine model 


\section{Describe some main structures and details}

Clamping mechanism (figure 5)

State 1: Piston rod carries positive pin. Positive pin is a cylindrical cylinder with a cone head, which is brought gradually by the piston to the hole of the negative pin. The bolt consists of two clamp plates and two springs. When the taper level of the positive pin has just been fitted to the negative pin hole, the force of the spring brake is applied, making the two clamp plates expand, and the positive pin is easily inserted. Immediately after that, the spring pulling the two clamps closed, the positive pin step was blocked, unable to pull it out.

State 2: When the piston needs to return (pull up), the system of pin negative, positive, inner tube (hammer) is also pulled up. This is a state of hammer lift.

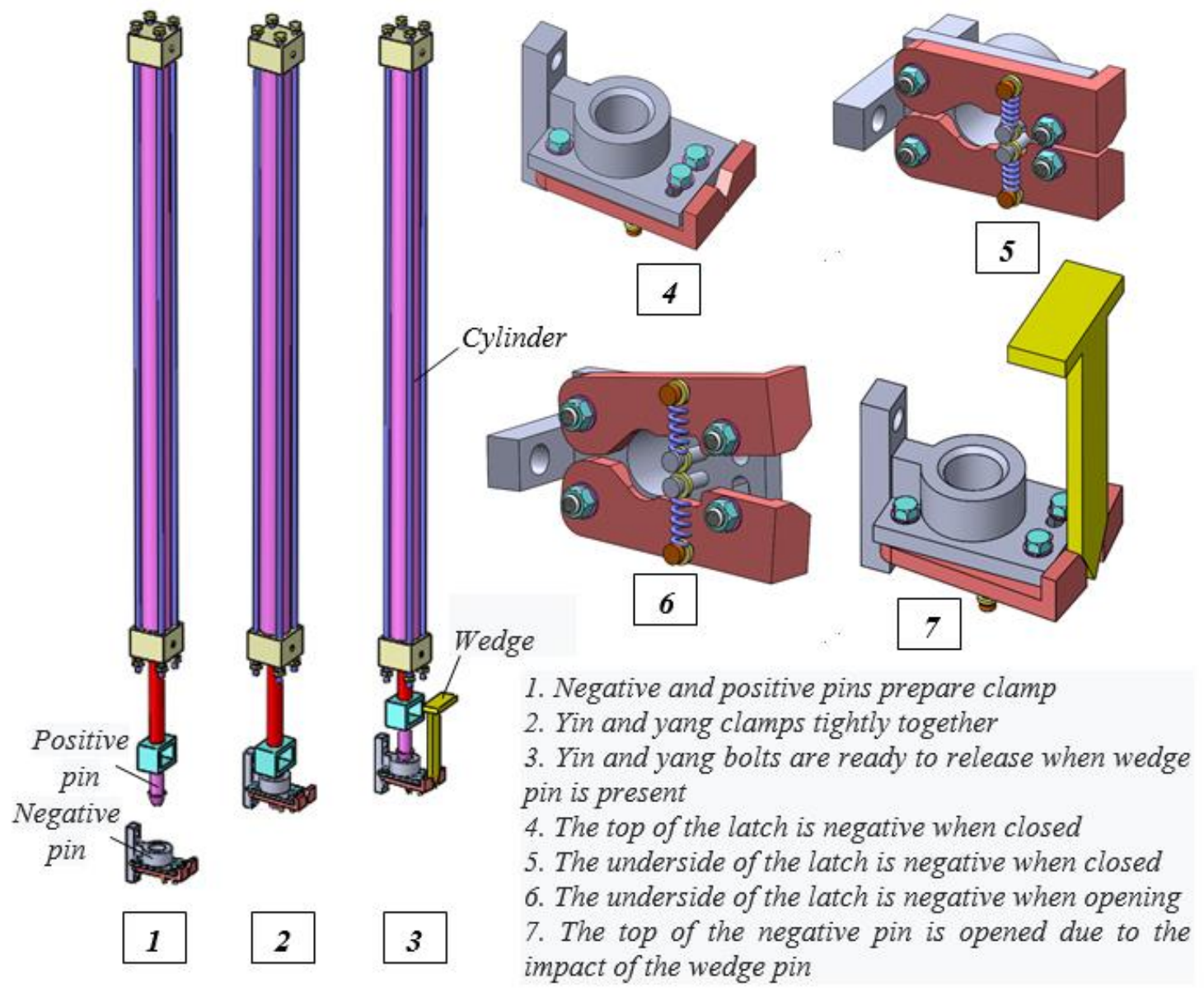

Figure 5. Description of clamping / releasing mechanism when driving piles

State 3: When the hammer is raised at the end of its stroke, the clutch slot in the two clamp plates of the negative pin is crushed by the wedge pin, causing the spring force to brake, causing the two clamps to open, the positive and negative 
pin apart. As a result, the negative pin and the inner tube (hammer) fall freely, hitting the pile head. As shown in Figure 3, we see that the inside of the inner tube has steps, the same steps will hit the pile cap, the force transmitted from the steps to the pile cap and from the pile cap to the pile, resulting in the pile settling into the ground. This is the piling state.

State 1, 2, 3 repeats (thanks to external control circuit) until the pile is finished. The pile cap is repositioned according to the steps (figure 3) by the operator's hand during the piling process.

Statuses 4, 5, 6, 7: Image description and clamp / release process of the negative pin.

\section{Main description and details (figure 6)}

Figure 6 shows typical details for a combined model of pile presses. These drawings are not sized, so there is no fabrication value. Design file has its own set of drawings, the author does not present here. Figure 6 shows typical details for a combined model of pile presses. These drawings are not sized, so there is no fabrication value. Design file has its own set of drawings, the author does not present here.

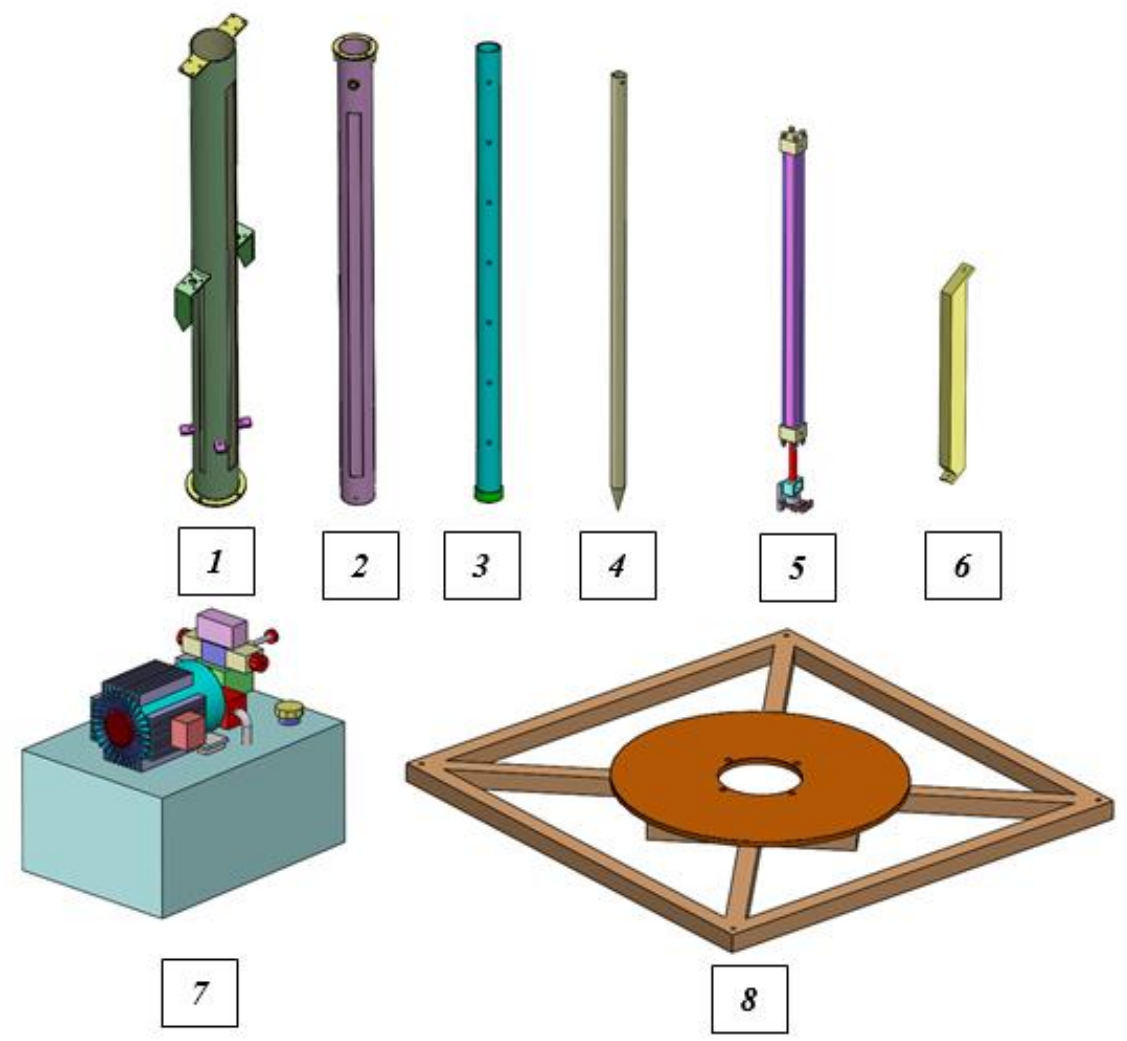

Figure 6. Some main details of the model [1. Outer tube; 2. Inner tube; 3. Hammer; 4. Pile; 5. Cylinder; 6. Struts; 7. Hydraulic power pack; 8. Base] 
- Outer and inner pipes: are cast steel pipes, the heart fits snugly together. The inner tube slides smoothly in the outer tube. This tubular design is different from the existing design of the working parts of the pile press, which means that a boxshaped steel truss system is used.

- Outer and inner pipes: are cast steel pipes, the heart fits snugly together. The inner tube slides smoothly in the outer tube. This tubular design is different from the existing design of the working parts of the pile press, which means that a boxshaped steel truss system is used.

- Pile: is a steel pipe, welded with a pointed steel tip as the tip of the pile. When driving or pressing the pile, the force is applied to the pile head, the tip of the pile sinks into the ground. After the pile is closed or pressed, we can also pull the pile up by bolting the top of the pile with the inner tube, the piston going back (up) and pulling the pile.

- Cylinder: Use two cylinders fitted on both sides of the outer tube. This type of cylinder has a stroke of 1 meter, pipe diameter $40 \mathrm{~mm}$, piston rod diameter $25 \mathrm{~mm}$. Struts: Use square box steel, a total of 4 struts, support around the outer tube to stabilize the whole machine.

- Hydraulic power pack: Use electric motor with capacity of $1 \mathrm{HP}$, maximum pressure of $15 \mathrm{Mpa}$, minimum pressure of $5 \mathrm{Mpa}$; have full distribution valve system, safety valve, pressure control valve; with pressure gauge and oil tank.

- Base: There is a round steel plate in the middle, outside is a square steel frame; At four right angles, drill holes to attach the anchor pin to the ground when pressing the pile (to counteract the soil's reaction). In the case of large pile presses, we replace them with a rectangular base and add counterweights that are loaded on top as currently used by the pile presses. If the pile is pressed in a narrow place, we use a long rectangular base and anchor the base to the ground.

\section{Calculate the model of pile driving and pressing machine combination}

\section{Energy feature 1 hammer hit the head of the pile}

We use the inner tube is a steel pipe with outer diameter of $152 \mathrm{~mm}$, inner diameter $140 \mathrm{~mm}$, length $2.4 \mathrm{~m}$. The hammer consists of a handle and a hammer head. Rolled is a steel pipe with an outer diameter of $114 \mathrm{~mm}$, an inner diameter of $98 \mathrm{~mm}$, and a length of $2.2 \mathrm{~m}$, with two sides cut off. The hammer head is solid round steel with a diameter of 
$137 \mathrm{~mm}$ and a height of $40 \mathrm{~mm}$. As an approximate compensation, consider that the hammer consists of only $114 \mathrm{~mm}$ outer prism steel tube, $98 \mathrm{~mm}$ inner diameter. With the density of steel is $\rho=7850 \mathrm{~kg} / \mathrm{m} 3$, we calculate the weight of the inner tube and the hammer as follows:

$$
\begin{aligned}
& \mathrm{m}_{1}=\rho \cdot \mathrm{V}_{1}=7850 \cdot 2,4 \cdot \pi \cdot\left(0,154^{2}-0,14^{2}\right) / 4+\approx 61(\mathrm{~kg}) \\
& \mathrm{m}_{2}=\rho \cdot \mathrm{V}_{2}=7850 \cdot 2,2 \cdot \pi \cdot\left(0,114^{2}-0,098^{2}\right) / 4+\approx 46(\mathrm{~kg})
\end{aligned}
$$

Total weight of inner tube and hammer is: $\mathrm{m}=\mathrm{m}_{1}+\mathrm{m}_{2}=61+46=107(\mathrm{~kg})$

When the hammer falls freely down a section $\mathrm{h}=0,9 \mathrm{~m}$ and hits the head of the pile, the hammer energy is equal to gravity:

$$
\mathrm{W}=\mathrm{A}=\mathrm{m} \cdot \mathrm{g} \cdot \mathrm{h}=107 \cdot 10 \cdot 0 \cdot 9=930 \mathrm{~J}
$$

Comment: We use the energy of 1 hammer as above to hit the pile head, the pile is less than $50 \mathrm{~mm}$ in diameter, sharpened, easily subsided to the ground. The smaller the pile, the easier it will sink, the heavier the hammer, the larger the range of movement, the greater the energy of one hammer stroke. We are designing a small model, it is necessary that the working principle is suitable, the energy of one hammer is big or small, we calculate to see the model's capacity, the result does not affect the model value.

\section{Calculate the pile pressure, pull the pile of the piston rod}

We use 2 cylinders, cylinder structure as shown in Figure 7. Its parameters are: piston diameter $0.04 \mathrm{~m}$, cylinder diameter $0.04 \mathrm{~m}$, piston rod diameter $0,025 \mathrm{~m}$.

- When both pistons come together (i.e. when pressing the pile): With hydraulic oil pressure in the cylinder from $\mathrm{p}_{1}=5.106 \mathrm{~Pa}$ to $\mathrm{p}_{2}=15.106$ $\mathrm{Pa}$, the applied force $\mathrm{F}$ is in the range from $\mathrm{F}_{1}$ winch $\mathrm{F}$. Their values are as follows:

$$
\begin{aligned}
& \mathrm{F}_{1}=2 \cdot \mathrm{p}_{1} \cdot \mathrm{S}=2 \cdot 5 \cdot 10^{6} \cdot \pi \cdot 0,04^{2} / 4 \approx 12566(\mathrm{~N}) \\
& \mathrm{F}_{2}=2 \cdot \mathrm{p}_{2} . \mathrm{S}=2 \cdot 15 \cdot 10^{6} \cdot \pi \cdot 0,04^{2} / 4 \approx 37700(\mathrm{~N})
\end{aligned}
$$

- When both pistons come back (i.e. when lifting the inner tube): With hydraulic oil pressure in the cylinder also from $\mathrm{p}_{1}=5.106 \mathrm{~Pa}$ to $\mathrm{p}_{2}=15.106$ $\mathrm{Pa}$, the applied force $\mathrm{F}$ is in the range from $\mathrm{F}_{3}$ to $\mathrm{F}_{4}$. Their values are as follows:

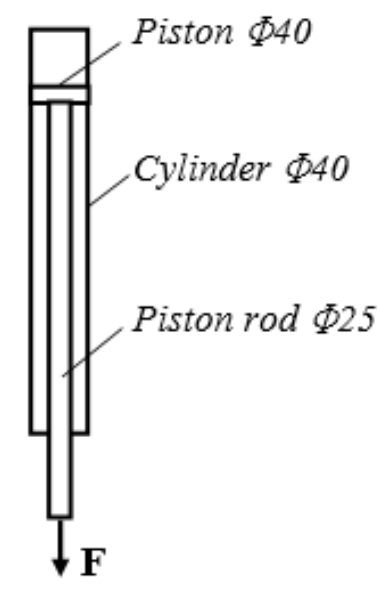

Figure 7. Cylindr

$$
\begin{aligned}
& \mathrm{F}_{3}=2 \cdot \mathrm{p}_{1} \cdot \mathrm{S}=2 \cdot 5 \cdot 10^{6} \cdot \pi \cdot\left(0,04^{2}-0,025^{2}\right) / 4 \approx 7658(\mathrm{~N}) \\
& \mathrm{F}_{4}=2 \cdot \mathrm{p}_{2} . \mathrm{S}=2 \cdot 15 \cdot 10^{6} \cdot \pi \cdot\left(0,04^{2}-0,025^{2}\right) / 4 \approx 22972(\mathrm{~N})
\end{aligned}
$$




\section{Comment:}

- With the forces $F_{1}$ and $F_{2}$ as above, plus the self load of the inner tube and hammer (they has a mass of $107 \mathrm{~kg}$, equivalent to a weight of about $1070 \mathrm{~N}$ ), we can press the sharp-tipped piles with the diameter of the pile body. The settlement is less than $50 \mathrm{~mm}$ in normal soil types. Here, we also do not care about our model that can squeeze the pile of diameter, what kind of soil is the pile, but we care whether that model presses the pile or not, the principle of operation. Is it suitable? The pressing of large or small piles is only due to the large or small capacity of the machine.

- With the above forces $\mathrm{F}_{3}$ and $\mathrm{F}_{4}$, it is also possible to lift the inner tube and hammer (they has a weight of $1070 \mathrm{~N}$ ), and at the same time it is possible to extract piles with a diameter of less than $50 \mathrm{~mm}$ that are sinking deep in the ground (this is predicted by experience, will check again when the model is finished fabricating). However, the large or small uptake of piles is due to the large or small capacity of the machine only, does not affect the value of the model we are designing.

\section{Conclusion}

The author presented the theory, referring to the current known pile driving and pressing machines, giving some main drawings and calculations related to the topic "Designing model combining driving machine, pile press" of author. The new feature of this topic is to combine two separate machines into one machine, convenient for users and significantly reducing costs. After the design is complete, the author will create a small model for research to build large machines, can register for intellectual property or participate in technical creation. At the same time, the small model is also used as teaching aids for students of construction and other related disciplines.

\section{References}

Nguyen Van Hung (2003). Construction Machinery. Science and Engineering Publishing, 189 198.

Webpage: https://dantri.com.vn/khoa-hoc-cong-nghe/che-tao-thanh-cong-may-ep-coc-ho-landuong-o-to-made-in-viet-nam-20161016141230159.htm

Webpage: https://lhe.com.vn/may-dong-coc-nang-luong-mat-troi-mz460

Webpage: https://vietnamese.alibaba.com/product-detail/tolhit-handheld-petrol-poweredguardrail-fence-vibrating-post-driver-hammer-60075628659.html 